\title{
Um Estudo Empírico sobre as Perspectivas de Ampliação das Relações Comerciais entre Brasil e China
}

\author{
Adriana Toledo Mendes', André Filipe Zago de Azevedo', Paulo Renato Soares Terra² \\ 'Universidade do Vale do Rio dos Sinos \\ ${ }^{2}$ Universidade Federal do Rio Grande do Sul
}

\section{Resumo}

Este artigo identifica os produtos brasileiros, a seis dígitos da NCM, com maiores perspectivas de ampliação de comércio com a China, através da avaliação da competitividade exportadora brasileira e do dinamismo importador chinês. A análise da competitividade brasileira se baseia no Índice de Vantagem Comparativa Revelada (IVCR), enquanto o dinamismo importador da China é obtido através da avaliação daqueles produtos que apresentaram o maior crescimento das importações no período 2000-2007, que coincide com a entrada da China na OMC. Além disso, identificou-se o grau de intensidade tecnológica desses produtos com maior potencial de crescimento das exportações brasileiras para a China. De um universo de mais de 5 mil produtos, apenas 92 produtos satisfizeram ambos os critérios, sendo tanto competitivos no Brasil como dinâmicos no mercado chinês, portanto, com possibilidades de ampliação do comércio bilateral. Observou-se que a pauta exportadora brasileira para a China é extremamente concentrada em poucos produtos, especialmente minérios, soja, celulose e óleos vegetais, onde o Brasil apresenta acentuada vantagem comparativa e a China um forte dinamismo importador, ou seja, as importações chinesas são intensas naqueles produtos que o Brasil apresenta competitividade.

Palavras Chave: China; Vantagem Comparativa Revelada; Competitividade; OMC.

\begin{abstract}
This paper identifies those Brazilian products, at six-digit level of NCM, with greater perspectives of increasing their exports to China, through the evaluation of the Brazilian export competitiveness and the Chinese import dynamism. The analysis of Brazilian competitiveness is based on the Index of Revealed Comparative Advantage (RCA), while the Chinese import dynamism is obtained by looking at those products which showed the greater increase in imports in the period 2000-2007, which coincides with China accession to WTO. Both indicators consider the HS classification at 06 digit level, in the years 2000, 2004, 2005, 2006 e 2007. Besides, it was identified the technological intensity degree of those Brazilian products with major potential of exports growth to China. From an universe of more than 5 thousand products, only 92 satisfied both criteria, being both competitive in Brazil and dynamic in the Chinese market, with great possibilities to increase the bilateral trade. It was possible to note that the Brazilian exports to China are highly concentrated in few products, especially ores, soy, cellulose and vegetable oils, where it shows comparative advantage and China a strong import growth, which Chinese imports seems to be intense in those products in which Brazil shows competitiveness.
\end{abstract}

Keywords: China; Revealed Comparative Advantage; Competitiveness; WTO. 


\section{INTRODUÇÃO}

A partir de 1978 a República Popular da China (China) iniciou um programa para o desenvolvimento de sua economia, um processo lento e gradual de abertura econômica. Três décadas mais tarde, em 2007,o país saltou da $7^{a}$ posição para a $3^{a}$ posição entre as potências econômicas mundiais. Atualmente, a China é a maior economia em crescimento no mundo, com um crescimento médio anual do Produto Interno Bruto de 9,5\% entre 1996 e 2007. Estima-se que antes de 2015 a China se torne o maior mercado do planeta, mantendo-se nesta média de crescimento. Em razão desse desempenho econômico, a China tornou-se um importante mercado para as exportações mundiais, com seu intercâmbio comercial com o mundo aumentando significativamente nos últimos anos, passando de US $\$ 851$ bilhões em 2003, para US\$ 2,2 trilhões em 2007, um crescimento de $156 \%$ em apenas cinco anos.

As relações comerciais entre Brasil e China foram impulsionadas pela necessidade comum de inserção política e econômica no cenário internacional, sendo impulsionadas a partir de 1974, quando ocorreu o reatamento das relações diplomáticas entre os países. Somente nos últimos 8 anos a China passou de $12^{\circ}$ para o $3^{\circ}$ lugar entre os principais destinos das exportações brasileiras. Somente em 2007, foram US\$ 23,3 bilhões em transações bilaterais. No entanto, o intercâmbio comercial entre Brasil e China ainda representa apenas $1 \%$ das trocas comerciais da China com o mundo. Ou seja, a China ainda é um mercado a ser melhor explorado pelo Brasil, o que justifica a escolha do tema deste artigo, que objetiva identificar aqueles produtos brasileiros com maior potencial de ampliação de exportação para aquele país.

A composição da pauta de exportação brasileira para a China se concentra principalmente em produtos básicos. Em 2007, foi composta por 73,8\% de produtos básicos, $18 \%$ de semimanufaturados e $8,2 \%$ de produtos manufaturados. Quando se examinam as exportações por intensidade tecnológica, o quadro não se altera muito, com a pauta sendo composta de $24,1 \%$ de commodities, $27,1 \%$ de produtos de baixa tecnologia, $42,4 \%$ de produtos de média tecnologia e apenas $6,4 \%$ de alta tecnologia. A questão que emerge a partir desta constatação é em que produtos o Brasil tem maior potencial competitivo no mercado chinês, ou seja, em quais produtos há possibilidades de ampliação efetiva de suas exportações para a China?

A análise da competitividade das exporta- ções brasileiras é realizada através do desempenho relativo das exportações do país em relação ao resto do mundo, utilizando-se o Índice de Vantagem Comparativa Revelada (IVCR), que tem sido amplamente utilizado pela literatura para esse fim (por exemplo, WAQUIL et al, 2004; RIBEIRO; POURCHET, 2004; CORONEL et al., 2007). Já a avaliação do dinamismo importador chinês se baseia na metodologia proposta por Machado e Serapião (2003), e consiste na identificação daqueles produtos que apresentaram o maior crescimento das importações no período recente, entre 2000 e 2007.

Esse artigo está dividido em 5 seções, além desta introdução. A próxima seção apresenta uma breve evolução do comércio bilateral entre Brasil e China no período de 1996 a 2007. A seção 3 apresenta, de forma sucinta, algumas evidências empíricas e formas de mensuração das vantagens comparativas e de intensidade tecnológica das exportações. A seção 4 mostra a metodologia adotada para identificar os produtos brasileiros mais propensos a expandirem suas exportações para o mercado chinês e os compara com aqueles efetivamente exportados, enquanto a seção 5 apresenta os principais resultados encontrados. Por fim, na última seção encontram-se as considerações finais.

\section{EVOLUCCÃO DO COMÉRCIO BILATERAL BRASIL-CHINA}

A relação diplomática entre Brasil e China remonta a década de 1970. Conforme Dick (2006), a relação sino-brasileira ocorreu de forma cautelosa, tendo como base "os relatórios de Hong Kong", material elaborado pelo consulado brasileiro entre os anos de 1969 e 1971, contendo esclarecimentos sobre as mudanças no processo político interno da China e seus reflexos na política internacional. Em maio de 1971, o Consulado brasileiro divulgou o possível interesse da China em se aproximar do Brasil. No final da década de 1960, o desempenho positivo da economia mundial atraía novos investimentos e o consumo de produtos básicos produzidos no Brasil pelos países desenvolvidos. Tal condição impulsionou a economia brasileira, consolidando o milagre econômico. O novo cenário internacional de perspectivas que se montava impulsionou o desenvolvimento de estratégias de melhor posicionamento do Brasil frente aos mercados externos, enfatizando agora o interesse nacional no bilateralismo. A China, por sua vez, necessitava abrir caminho para o ocidente, elimi- 
Tabela 1 - Intercâmbio Comercial Brasil - China (em US\$ Mil - FOB)

\begin{tabular}{|r|r|r|r|r|r|}
\hline Ano & $\begin{array}{c}\text { Exportações } \\
\text { brasileiras } \\
\text { (A) }\end{array}$ & $\begin{array}{c}\text { Importações } \\
\text { brasileiras } \\
(\mathbf{B})\end{array}$ & S aldo (A-B) & $\begin{array}{c}\text { Corrente de } \\
\text { comércio } \\
(\mathbf{A}+\mathbf{B})\end{array}$ & $\begin{array}{c}\text { Participação do } \\
\text { comércio bilateral no } \\
\text { comércio exterior } \\
\text { brasileiro (em \%) }\end{array}$ \\
\hline 1996 & 1.113 .829 & 1.132 .884 & -19.055 & 2.246 .713 & 2,22 \\
\hline 1997 & 1.088 .215 & 1.166 .421 & -78.206 & 2.254 .636 & 2,00 \\
\hline 1998 & 904.878 & 1.033 .807 & -128.929 & 1.938 .685 & 1,78 \\
\hline 1999 & 676.143 & 865.220 & -189.077 & 1.541 .363 & 1,58 \\
\hline 2000 & 1.085 .302 & 1.222 .099 & -136.797 & 2.307 .401 & 2,08 \\
\hline 2001 & 1.902 .123 & 1.328 .390 & 573.733 & 3.230 .513 & 2,84 \\
\hline 2002 & 2.520 .979 & 1.553 .994 & 966.985 & 4.074 .973 & 3,78 \\
\hline 2003 & 4.533 .364 & 2.147 .801 & 2.385 .563 & 6.681 .165 & 5,50 \\
\hline 2004 & 5.441 .746 & 3.710 .478 & 1.731 .268 & 9.152 .224 & 5,74 \\
\hline 2005 & 6.834 .997 & 5.354 .520 & 1.480 .477 & 12.189 .517 & 6,34 \\
\hline 2006 & 8.402 .369 & 7.990 .416 & 411.953 & 16.392 .785 & 7,15 \\
\hline 2007 & 10.748 .814 & 12.620 .199 & -1.871 .385 & 23.369 .013 & 8,31 \\
\hline
\end{tabular}

Fonte: MDIC-SECEX - Elaboração Própria.

nando seu isolamento econômico no período de Mao Tsé-Tung (DICK, 2006).

Após a morte de Mao Tsé-Tung em 1976, o governo chinês deu início a reformas e estratégias de crescimento econômico orientadas à cooperação econômica internacional para a concretização das metas de expansão e modernização do país. Neste período, os governos brasileiro e chinês intensificaram suas relações diplomáticas e, em 1978, assinaram o Acordo Comercial Bilateral, formalizando assim uma parceria comercial entre ambos os países. Apesar da busca de um processo de maior integração entre os países, o comércio bilateral até recentemente não havia crescido significativamente. No período compreendido entre 1996-2000, a participação das transações bilaterais no comércio exterior brasileiro nunca foi superior a 2,2\%. Contudo, desde o final de 1999, o comércio entre os dois países vem crescendo de forma consistente. As exportações passaram de US\$ 1,085 bilhão em 2000, para US\$ 10,749 bilhões em 2007, um crescimento de $891 \%$ (tabela 1). As importações por sua vez, cresceram de US $\$ 1,222$ bilhão para US\$12,620 bilhões no mesmo período, ou seja, $933 \%$. Essas taxas de crescimento foram muito superiores à média brasileira, permitindo que a participação do comércio bilateral Brasil-China no comércio total brasileiro quadruplicasse entre 2000 e 2007, passando de apenas 2,08\% para $8,31 \%$.

Para o MRE (2008), a entrada da China na
OMC abriu novas oportunidades para os exportadores brasileiros, incluindo commodities, e até produtos de alta tecnologia, como aviões. De acordo com Barbosa e Mendes (2006), a expansão da economia chinesa teve um impacto positivo para a economia brasileira, e pode ser dividida em duas linhas: indireto e direto. $\mathrm{Na}$ primeira situação, encontram-se os fatores relacionados ao vigor da economia internacional no período de 2003 a 2005. Os superávits comerciais chineses acabaram favorecendo as transferências de capitais para as economias emergentes, além de elevarem a demanda de outros países que importam produtos brasileiros. Já os impactos diretos, segundo os autores, são aqueles vinculados ao aumento da demanda chinesa por commodities agrícolas e minerais. Segundo dados da OMC, 19\% das importações chinesas são de produtos agrícolas e $7 \%$ de minerais. A pauta de exportações brasileiras para China é concentrada justamente em alguns produtos desses setores, sendo que apenas dois grupos de produtos foram responsáveis por $62 \%$ do total das vendas do Brasil para China, em 2007 (tabela 2). Esses dois principais grupos de produtos, "Minérios escorias e cinzas" e "Sementes e frutos oleaginosos, grãos" tem se revezado como os mais importantes setores de exportação brasileiros para a China desde o início do século XXI. Portanto, apesar das exportações brasileiras para China no período de 2000 a 2007 terem crescido dramaticamente, a pauta ainda é composta principalmente 
de produtos com baixo valor agregado e baixa intensidade tecnológica.

Segundo o MRE (2008), o comércio entre Brasil e China é amparado por uma lista de produtos beneficiados com tarifas reduzidas. Nota-se, no entanto, que os produtos que fazem parte apenas da pauta negociadora brasileira na OMC, as negociações bilaterais de acesso são multilateralizadas no ato da entrada do país. Ou seja, o Brasil se beneficiará também com outras linhas tarifárias negociadas por outros países. Portanto, a partir do ingresso da China na OMC, em 2001, as empresas brasileiras exportadoras já tiveram maiores facilidades para entrar no mercado chinês. Entre os produtos que o Brasil conseguiu redução do grau de protecionismo estão carnes bovinas e de frango, café em grão, café solúvel, soja em grão, óleo de soja, máquinas e equipamentos, e peças automotivas. Os produtos sujeitos a quotas de importação na China são aqueles cuja importação, segundo o governo chinês, pode inibir a indústria doméstica. Dentre os itens que requerem licença para importação, há uma lista resumida dos que afetam as relações comerciais entre o Brasil e a China: Fibra acrílica, condicionadores de ar e compressores, cereais, veículos automotores e peças, borracha natural, fibra de poliéster, açú- car, tabaco e produtos de tabaco, óleos vegetais, pneus, e vinhos (MRE, 2008). Portanto, boa parte do crescimento das exportações brasileira para a China após 2001 se deve ao maior grau de abertura comercial resultante da entrada da China na OMC.

\section{VANTAGENS COMPARATIVAS E INTEN- SIDADE TECNOLÓGICA DAS EXPORTA- ÇÕES}

\section{I Vantagens Comparativas: Mensuração e evidências empíricas}

O Índice de Vantagem Comparativa Revelada (IVCR), desenvolvido originalmente por Balassa (1965), continua sendo um dos instrumentos mais utilizados para medir as vantagens comparativas de um país, sendo escolhido para mensurar o dinamismo exportador brasileiro neste artigo. Através dele, mensura-se o desempenho relativo das exportações de um determinado produto, ou categoria de produtos de um país ou região com o mundo. Isto é, se o IVCR de um determinado produto for maior do que um, o país ou bloco apresenta vantagens comparativas em relação ao resto do mundo. Quanto mais alto for o IVCR,

Tabela 2 - Exportações Brasileiras para a China por principais grupos de produtos, 2000-2002 / 2005-2007 em US\$ milhões

\begin{tabular}{|c|c|c|c|c|c|c|c|c|c|c|}
\hline PRINCIPAIS GRUPOS DE PRO DUTOS & 2000 & $(\%)$ & 2001 & $(\%)$ & 2002 & $(\%)$ & 2005 & $(\%)$ & 2007 & $(\%)$ \\
\hline MINERIOS, ESCORIAS E CINZAS & 273,8 & 25,2 & 491,0 & 25,8 & 608,9 & 24,2 & $1.891,8$ & 27,7 & $3.807,9$ & 35,4 \\
\hline $\begin{array}{l}\text { SEMENTES E FRUT OS OLEAGINOSOS, } \\
\text { GRAOS, SEMENTES }\end{array}$ & 337,4 & 31,1 & 537,7 & 28,3 & 825,7 & 32,8 & $1.717,1$ & 25,1 & $2.831,9$ & 26,3 \\
\hline $\begin{array}{l}\text { COMBUST IVEIS MINERAIS, OLEOS } \\
\text { MINERAIS, CERAS MINERAIS }\end{array}$ & 36,1 & 3,3 & 39,9 & 2,1 & 0,0 & 0,0 & 558,1 & 8,2 & 840,2 & 7,8 \\
\hline FERRO FUNDIDO, FERRO E ACO & 38,5 & 3,5 & 57,0 & 3,0 & 140,0 & 5,6 & 527,8 & 7,7 & 336,3 & 3,1 \\
\hline $\begin{array}{l}\text { PAST AS DE MADEIRA OU MATERIAS } \\
\text { FIBROSAS CELULOSICAS }\end{array}$ & 54,2 & 5,0 & 127,3 & 6,7 & 114,2 & 4,5 & 270,1 & 4,0 & 423,5 & 3,9 \\
\hline $\begin{array}{l}\text { PELES,EXCET O A PELETERIA (PELES } \\
\text { COM PELO), E COUROS }\end{array}$ & 23,9 & 2,2 & 55,2 & 2,9 & 88,2 & 3,5 & 250,2 & 3,7 & 490,4 & 4,6 \\
\hline $\begin{array}{l}\text { GORDURAS, OLEOS E CERAS ANIMAIS } \\
\text { OU VEGET AIS, ET C. }\end{array}$ & 21,5 & 2,0 & 5,4 & 0,3 & 126,4 & 5,0 & 172,1 & 2,5 & 322,8 & 3,0 \\
\hline $\begin{array}{l}\text { REAT ORES NUCLEARES, CALDEIRAS, } \\
\text { MAQUINAS, MECANICOS }\end{array}$ & 31,1 & 2,9 & 88,3 & 4,6 & 108,8 & 4,3 & 259,2 & 3,8 & 235,3 & 2,2 \\
\hline $\begin{array}{l}\text { FUMO (T ABACO) E SEUS SUCEDANEOS } \\
\text { MANUFAT URADOS }\end{array}$ & 50,3 & 4,6 & 56,1 & 3,0 & 69,4 & 2,8 & 248,8 & 3,6 & 271,3 & 2,5 \\
\hline $\begin{array}{l}\text { MADEIRA, CARVAO VEGET AL E OBRAS } \\
\text { DE MADEIRA }\end{array}$ & 33,7 & 3,1 & 46,2 & 2,4 & 78,3 & 3,1 & 148,0 & 2,2 & 133,7 & 1,2 \\
\hline SUBTOTAL & 900,6 & 83,0 & $1.504,1$ & 79,1 & $2.160,0$ & $\mathbf{8 5 , 7}$ & $6.043,1$ & 88,4 & $9.693,2$ & $\mathbf{9 0 , 2}$ \\
\hline DEMAIS GRUPOS DE PRO DUTOS & 184,7 & 17,0 & 398,0 & 20,9 & 361,0 & 14,3 & 791,9 & 11,6 & $1.055,6$ & 9,8 \\
\hline TO TAL GERAL & $1.085,3$ & 100 & $1.902,1$ & 100 & $2.521,0$ & 100 & $6.835,0$ & 100 & $10.748,8$ & 100 \\
\hline
\end{tabular}

Fonte: MDIC-SECEX / Aliceweb - Elaboração Própria. 
maior será a vantagem do país comparada aos demais países na produção do produto examinado. Se o resultado encontrado for igual a um, o país desfruta da mesma competitividade média vigente no mercado internacional. Por fim, se for menor do que um, o país ou bloco é definido como tendo desvantagem comparativa revelada naquele produto. A expressão algébrica é dada por:

$$
I V C R_{b i}=\frac{X_{b i}}{X_{b t}} / \frac{X_{m i}}{X_{m t}}
$$

duto i;

Onde:

$\boldsymbol{X}_{\boldsymbol{b i}}:$ valor das exportações do país b do pro-

$\boldsymbol{X}_{b t}:$ valor total das exportações do país b; produto $\mathrm{i} ;$

$\boldsymbol{X}_{m i}^{b t^{*}}:$ valor das exportações mundiais do

$\boldsymbol{X}_{\boldsymbol{m} \boldsymbol{i}}:$ valor total das exportações mundiais.

Inicialmente, buscou-se calcular o índice de vantagem comparativa revelada dos produtos brasileiros a 6 dígitos do NCM, onde a razão entre as exportações do país $\mathbf{b}$ do produto $\mathbf{i}$ e o valor total das exportações do país $\mathbf{b}\left(X_{b} / X_{b}\right)$, e a razão do valor das exportações mundiais do produto i e o valor total das exportações mundiais $\left(X_{m} / X_{m}\right)$ definem o seu resultado. Os indicado- res mostram o dinamismo exportador brasileiro, apontando os produtos que apresentam maior e menor competitividade.

Tais indicadores são baseados nos fluxos comerciais e base de dados fornecidos pela Secretaria do Comércio Exterior (SECEX) do Ministério do Desenvolvimento, Indústria e Comércio do Brasil (MDIC), disponível por meio do Sistema de Análise das Informações do Comércio Exterior (ALICEWEB). Estes dados estão discriminados em exportação e importação, e estão enumerados de 1 a 99, de acordo com a Nomenclatura Comum do Mercosul (NCM), correspondendo a todos os produtos que são objeto de importação e exportação. Os dados referentes as importações chinesas foram obtidos no banco de dados United Nations Commodity Trade Database (COMTRADE).

Alguns estudos realizados recentemente, abordaram as características do comércio entre Brasil e China empregando o IVCR, juntamente com outros indicadores, entre eles o de intensidade tecnológica. O trabalho de Ribeiro e Pourchet (2004), no intuito de identificar o padrão de comércio Brasil-China no período de 1999 e 2003, aplicou o IVCR na análise do dinamismo exportador brasileiro. $\mathrm{O}$ primeiro aspecto que chamou a atenção dos autores foi a importância dos produtos básicos na pauta das exportações brasileiras para a China, cerca de 55\% das exportações na média do período de 2001-2003, participação superior as exportações totais do país, que no mesmo período representava $27,9 \%$. Segundo os autores, 47,5\% das vendas para China em 2003 referiam-se a apenas dois setores: agropecuária e extrativa mineral, $29,2 \%$ e $18,3 \%$ respectivamente, sendo que mais de $90 \%$ referem-se a apenas um produto, a soja no primeiro setor, e o minério de ferro no segundo. Outro fato observado pelos autores foi que produtos de grande peso na pauta exportadora brasileira, como a soja, a celulose e o aço eram produtos classificados como dinâmicos no mercado chinês.

Já Ferraz e Ribeiro (2004), além do IVCR, aplicaram o indicador de intensidade tecnológica em sua análise de desempenho das exportações brasileiras totais no período de 1996-2002. Os autores concluíram que os produtos manufaturados representam cerca de $55 \%$ a $60 \%$ da pauta exportadora brasileira para o mundo, sendo um pouco mais de $1 / 3$ das vendas, concentradas em produtos agrícolas. Os autores verificaram também que as exportações do Brasil e da China para o mundo, segundo a intensidade tecnológica, são de produtos de baixa e média-baixa intensidade. Um indício similar foi obtido por Mattos (2008), que para analisar o período de 1989 a 2006, aplicou além do IVCR, o Índice de Orientação Regional (IOR) e o Índice de Intensidade do Comércio (IIC). $\mathrm{O}$ autor ainda destacou que a China movimentava um comércio de US\$ 1,4 trilhão ao ano, porém o Brasil representava apenas $1 \%$ deste montante.

Nos estudos já realizados, os autores constataram que a maior parte das exportações brasileiras para a China é constituída de commodities primárias, com destaque para a soja. Coronel et al (2007), em seu estudo, analisaram a competitividade da soja brasileira em relação à China. Para mensurar os dados, os autores utilizaram o IVCR juntamente com o IOR. Os valores encontrados para o IVCR foram em média, crescentes ao longo do período analisado, 1992 a 2004. O melhor resultado obtido foi em 2004, quando se observou um crescimento de aproximadamente $147,81 \%$ em relação a 1992 , o que indicou que a sojicultura brasileira é um setor competitivo e com grande importância na pauta de exportações brasileiras. Já o IOR para China indicou que a exportação de soja está orientada 
para este bloco asiático, desde $1997 .^{1}$

\subsection{Grau de intensidade tecnológica: Mensuração e evidências empíricas}

Segundo Haguenauer (1989) e Bernardes (2003), a partir dos anos 1960, o desenvolvimento tecnológico passou a ser visto como indicador do crescimento econômico, e assim, as agências governamentais, organizações multilaterais e instituições produtoras de informações buscam meios de mensurar a intensidade tecnológica. Em 1963, a Organização para Cooperação do Desenvolvimento Econômico ${ }^{2}$ (OCDE), editou um manual denominado, Manual Frascati ${ }^{3}$, o que originou uma série de manuais metodológicos para mensurar as atividades de inovação tecnológica. Para Bernardes (2003), as pesquisas realizadas na década de 1960 para construção de indicadores de ciência e tecnologia (C\&T), tiveram como balizador o Manual Frascati.

Nas décadas de 1970 e 1980, foram introduzidos os indicadores de balanço de pagamento tecnológico e os indicadores de output (resultados). Como exemplo, citam-se as produções científicas e tecnológicas (patente), que ainda hoje se constituem como o maior indicador da capacidade de inovação. No final da década de 1990, iniciou-se uma nova fase

\footnotetext{
1 Inúmeros outros estudos mensuraram a competitividade de países ou blocos através do IVCR. Neto (1999) analisou a criação e desvio de comércio no Mercosul, Kume e Piani (2005) e Bender (2006), realizaram trabalhos referentes à Alca, os primeiros quantificaram o incremento das exportações e das importações brasileiras provocado pela Alca, e o segundo analisou o reflexo do bloco em relação aos países das Américas. Celestini (2006) identificou os produtos do vestuário brasileiro com potencial exportador. Holanda (2002) realizou um estudo empírico do comportamento da vantagem comparativa de um grupo de países do leste asiático. Maia (2002) analisou o impacto da abertura econômica sobre as exportações agrícolas do Brasil, enquanto Barbosa e Waquil (2001) e Waquil et al. (2005) analisaram as perspectivas das exportações agrícolas brasileiras para a ALCA e União Européia, respectivamente.

2 A Organização para a Cooperação e o Desenvolvimento Econômico (OCDE), criada em 30 de setembro de 1961, tem como objetivo promover políticas que busquem alcançar o mais alto nível de desenvolvimento econômico sustentável e de emprego, e um padrão de vida progressivamente melhor nos países membros. Contribuir para expansão do comércio mundial (calcada no multilateralismo e na não discriminação, em conformidade com as obrigações internacionais), e para a expansão econômica estável, tanto nos país membros quanto nos não membros. Seus paises membros são: Alemanha, Áustria, Bélgica, Canadá, Dinamarca, Espanha, Estados Unidos, França, Grécia, Holanda, Irlanda, Islândia, Itália, Luxemburgo, Noruega, Portugal, Reino Unido, Suécia, Suíça e Turquia (Manual de Oslo, 1997).

3 Faz parte do sistema estatístico dos países-membros da OCDE. A primeira versão surgiu em 1963, com o objetivo de uniformizar estatísticas e criar indicadores fidedignos e comparáveis, fornecendo definições e classificações internacionais.
}

nas pesquisas estatísticas de inovação, incorporando ou ampliando os conceitos metodológicos. Esta nova etapa estuda a inovação não apenas como resultado das rotinas a intensidade de pesquisas e desenvolvimento (P\&D), mas como resultado dos processos de aprendizagem (BERNARDES, 2003). Nos anos 1990, boa parte das pesquisas baseou-se no Manual de $\mathrm{Oslo}^{4}$, investigando setores industriais e serviços. Este manual passou por várias revisões e alterações, visando harmonizar a coleta e as análises. Para Sirilli (1998), o Manual de Oslo abrange uma cobertura maior do que as aplicadas no Manual Frascati, pois este último restringe o levantamento às empresas com atividade de $\mathrm{P} \& \mathrm{D}$ regulares, deixando de fora as de $\mathrm{P} \& \mathrm{D}$ irregulares.

Segundo Furtado e Carvalho (2005) e Markwald (2004), o indicador de intensidade de P\&D é o mais aplicado pela OCDE. Em 1992, foi criada uma nova classificação baseada em indicadores como gasto em P\&D e o gasto em tecnologia incorporada em bens intermediários e de investimento. Atualmente, a classificação da OCDE é baseada no indicador de intensidade de P\&D (Gasto em P\&D / valor adicionado, ou gasto em $\mathrm{P} \& \mathrm{D}$ / produção), sendo dividida em quatro categorias:

- Alta intensidade tecnológica: setor aeroespacial, farmacêutico, de informação, eletrônica, telecomunicações, e instrumentos;

- Média-alta intensidade tecnológica: setores de material elétrico, veículos automotores, química (excluído o setor farmacêutico), ferroviários, equipamentos de transporte, máquinas e equipamentos;

- Média-baixa intensidade tecnológica: setores de construção naval, borracha e produtos plásticos, coque, produtos refinados metálicos, metalurgia básica e produtos metálicos;

- Baixa intensidade tecnológica: outros setores e de reciclagem, madeira, papel e celulose, editorial e gráfica, alimentos, bebidas e fumo, têxtil de confecção, couro e calçados.

Conforme Furtado e Carvalho (2005), a classificação por intensidade tecnológica permite identificar diferenças estruturais entre países desenvolvidos e em desenvolvimento. Nas nações desenvolvidas, a intensidade tecnológica mostra

\footnotetext{
4 O Manual de Oslo, foi redigido por especialistas de cerca de 30 países que coletaram e analisaram dados sobre inovação. O Manual apresenta um conjunto substancial de diretrizes que podem ser usadas para desenvolver indicadores comparáveis de inovação nos países membros da OCDE. Basicamente analisa o balanço de pagamentos de tecnologia e estatísticas de inovação (Manual de Oslo, 1997).
} 
a velocidade em que estas nações se adaptam as novas tecnologias, e nos paises em desenvolvimento mostra os esforços relativos ao processo de transferência internacional de tecnologia. Os autores identificaram que as maiores diferenças entre países desenvolvidos e países em desenvolvimento ocorrem nos setores de média e alta tecnologia, que são atribuídas à especialização produtiva. Para os autores, quanto maior for a intensidade tecnológica, maior é o indício da existência de uma indústria sólida e uma acentuada especialização produtiva. Em contrapartida, o Brasil apresenta fraqueza nos setores de alta tecnologia e falta de especialização. Já nos setores de baixa (alimentos, têxtil, madeira, minerais não-metálicos, metalúrgica) e média-baixa (maquinaria, borracha e plásticos) tecnologia, o Brasil encontra-se numa posição mais favorável. $\mathrm{O}$ que explica por que nesses setores o Brasil acumula suas vantagens competitivas (KATZ e STUMPO, 2001).

Furtado e Carvalho (2005), que avaliaram a intensidade tecnológica brasileira em comparação com os países membros da OCDE, concluíram que a indústria manufatureira brasileira apresenta uma intensidade tecnológica $(1,5 \%)$ bem aquém a de todos esses países. ${ }^{5}$ Segundo os autores, o grupo da OCDE pode ser subdividido em quatro intensidades: líderes com intensidade tecnológica superior a 8\% (Japão e EUA), outro grupo de países europeus próximos com intensidade entre $6 \%$ e $7 \%$ (Alemanha, França e Reino Unido), um terceiro grupo de nações que exibem patamar intermediário de $4 \%$ (Coréia, Noruega e Canadá) e, por fim, o grupo de países atrasados, com intensidade de 2\% (Itália e Espanha).

Negri (2005), em estudo mais recente sobre exportações brasileiras para a China, analisou indicadores de competitividade e desempenho, concluindo que no período de 1996 a 2003, os produtos de alta intensidade tecnológica cresceram $350 \%$, representando $40 \%$ das importações chinesas do Brasil, enquanto os produtos de média intensidade representaram $23 \%$. Já o segundo segmento de maior crescimento na pauta de importações foi o de baixa intensidade tecnológica (183\%), representando $7 \%$ das importações da China. Em contrapartida, as exportações do Brasil, neste mesmo período, cresceram mais de $300 \%$, sendo os produtos de baixa intensidade responsáveis por mais de $80 \%$ das exportações, sendo as commodities primárias responsáveis pelo maior

\footnotetext{
5 Para Furtado e Carvalho (2005), o desenvolvimento tecnológico brasileiro aconteceu de forma tardia, o que deixa o setor industrial muito aquém do desenvolvimento obtido pelos países desenvolvidos. Neste contexto, é cada vez mais comum a busca pelo conhecimento tecnológico, visando à adaptação da indústria ao novo mercado que se apresenta.
}

crescimento, ou seja, $62 \%$ das exportações, sendo o setor agrícola o mais beneficiado.

\section{METODOLOGIA}

Esta seção tem como objetivo descrever o procedimento metodológico para identificar a competitividade brasileira e o dinamismo importador chinês. A metodologia deste trabalho se baseia em Machado e Serapião (2003), e consiste na combinação do índice da Vantagem Comparativa Revelada (IVCR) das exportações brasileiras com o dinamismo importador chinês. As principais diferenças entre os dois trabalhos se referem à utilização do indicador de intensidade tecnológica, o país estudado e o período de análise.

Inicialmente, foram obtidos os produtos brasileiros exportados para o mundo, nos anos $2000^{6}, 2004,2005,2006$ e 2007, totalizando 8.059 produtos diferentes, a 8 dígitos do código NCM. Após, os produtos foram agregados para seis dígitos do código NCM, passando a amostra para um total de 5.302 produtos. $^{7}$ Para a identificação dos produtos brasileiros com maiores oportunidades comerciais no mercado chinês foi definido o universo de oportunidades, considerando-se a existência e a competitividade da oferta exportável brasileira e o crescimento das importações chinesas. Para tal, aplicaram-se três critérios:

i) Oferta Exportável Brasileira: Da amostra inicial de 5.302 produtos, selecionou-se aqueles cujas exportações brasileiras anuais totais em 5 anos (2000, 2004 a 2007) foram superiores a US\$ 10 milhões. Esta seleção visou diminuir a amostra de produtos e levar em consideração somente produtos com valores significativos, que apresentavam uma efetiva capacidade exportadora. Como resultado, a amostra original foi reduzida para 426 produtos do NCM a 6 dígitos.

ii) Dinamismo Exportador Brasileiro: Desses produtos restantes foi calculado o IVCR, selecionando-se aqueles que apresentaram vantagem comparativa revelada em 2007, restando 280 produtos a 6 dígitos do NCM.

iii) Grau de Dinamismo das Importações Chinesas: Os produtos com maior dinamismo impor-

\footnotetext{
$6 \mathrm{O}$ ano de 2000 foi utilizado, pois se trata do ano imediatamente anterior à entrada da China na OMC em 2001, possibilitando assim, comparações com um período anterior à entrada da China na OMC. 7 Para analisar a evolução das exportações brasileiras, inicialmente faz-se necessário compatibilizar os dados do Sistema Harmonizado (SH), de 8 dígitos para 6 dígitos do NCM. A China adotou o Sistema Harmonizado de Designação e de Codificação de Mercadorias (SH) em 1992.
} 
tados pela China foram obtidos comparando-se o desempenho de suas importações, com a média das importações totais do país. A amostra final obtida (280 produtos) foi dividida em 2 grupos, conforme o grau de dinamismo importador chinês. Aqueles produtos cuja taxa de crescimento das importações chinesas foi superior a $400 \%$ (crescimento médio das exportações chinesas no período) entre 2000 e 2007, foram considerados "dinâmicos". Aqueles produtos cuja taxa de crescimento das importações chinesas foi igual ou inferior a $400 \%$, foram considerados "cadentes".

A partir desse procedimento, foi possível identificar aqueles produtos que apresentaram tanto um dinamismo exportador brasileiro como um dinamismo importador chinês, representando aqueles produtos com maior potencial de ampliação das exportações brasileiras no mercado chinês

\section{RESULTADOS}

A amostra final resultante da metodologia aplicada resultou em 280 produtos. Destes, 218 produtos compuseram a pauta de exportação brasileira para a China nos anos de 2000, 2004, 2005,2006 e $2007 .{ }^{8}$ Observa-se que apenas $32,9 \%$, ou 92 dos 280 produtos analisados, nos quais o Brasil possuía vantagem comparativa revelada em 2007, eram dinâmicos no mercado chinês, ou seja, produtos com a taxa de crescimento das importações chinesas superiores a $400 \%$ entre 2000 e 2007 (tabela 3). O foco das exportações brasileiras para o mercado chinês deve se concentrar nestes produtos, pois além de o Brasil ser competitivo,

8 Portanto, foram identificados 62 produtos com vantagem comparativa, mas que ainda não foram comercializados no mercado chinês, representando um outro possível nicho de mercado a ser explorado pelo Brasil.

Tabela 3 - Produtos com Dinamismo Importador e Vantagem Comparativa Revelada*

\begin{tabular}{|l|c|c|}
\hline Classificação & $\mathbf{N}^{\mathbf{0}}$ de produtos & Total \\
\hline Dinâmicos & 92 & $32,9 \%$ \\
\hline Cadentes & 188 & $5,0 \%$ \\
\hline Total & 280 & $100,0 \%$ \\
\hline
\end{tabular}

Fonte: Comtrade - Elaboração Própria.

* Dos 426 produtos analisados, 280 possuem Vantagem Comparativa Revelada. a China apresenta uma demanda de importações crescendo acima da média..

Entre os 92 produtos classificados como "dinâmicos", os três primeiros produtos da pauta, em ordem decrescente do IVCR, são: "ferroniobio", "suco de laranja" e "cordéis de sisal / outras fibras" (tabela 4). " "Ferroniobio" constituiu-se no produto que apresentou o maior IVCR, de 63,32, com as exportações brasileiras para a China somando US\$ 206 milhões em 2007, uma participação de apenas $15,35 \%$ no total exportado pelo país, sendo "apenas" o oitavo produto mais exportado para a China. Assim, o elevado IVCR somado ao grande crescimento observado nas importações chinesas, de $1.822 \%$ entre 2000 e 2007, revelam um elevado potencial de crescimento das exportações brasileiras deste produto para a China. Já "suco de laranja", com o segundo maior IVCR $(55,2)$, também mostrou um grande dinamismo importador chinês (1.388\%), mostrando um forte potencial de crescimento comercial para aquele mercado. Vale ressaltar que dos três produtos com maior IVCR, "cordéis de sisal ${ }^{10}$ / outras fibras", com IVCR de 42,3, foi o único não exportado para a China nos anos de 2000, 2004, 2005, 2006 e 2007, mas mostra um grande potencial para penetrar naquele mercado.

Quando se observa os produtos mais exportados pelo Brasil para a China a seis dígitos da NCM, percebe-se uma forte concentração em produtos primários: Minérios de ferro, grãos de soja, óleos bruto e pastas químicas de madeira (tabela 5). O perfil da pauta de exportação tem se mantido ao longo do tempo, como pode ser observado em Ribeiro e Pourchet (2004), Negri (2005), Castilhos (2007) e Mattos (2008). Além disso, ela não segue uma ordem crescente de "nível competitividade", ou seja, produtos com maiores IVCR não são necessariamente os mais exportados, como é o caso de "ferroniobio", conforme destacado acima. No entanto, especialmente os mais exportados, "minérios de ferro" e "outros grãos de soja", também são bastante competitivos, com IVCR superior a 20.

Chama a atenção que da pauta dos produtos

\footnotetext{
9 Dos 188 produtos classificados como "cadentes", ou seja, produtos cuja taxa de crescimento das importações chinesas foi igual ou inferior à média de $400 \%$ observada entre 2000 e 2007, 35 produtos apresentaram um IVCR elevado (acima de 10).

10 Do sisal, utiliza-se principalmente a fibra das folhas que, após o beneficiamento, é destinada majoritariamente à indústria de cordoaria (cordas, cordéis, tapetes etc). O sisal também é utilizado na produção de estofados; pasta para indústria de celulose; produção de tequila; tapetes decorativos; remédios; biofertilizantes; ração animal; adubo orgânico e sacarias. As fibras podem ser utilizadas também na indústria automobilística, substituindo a fibra de vidro.
} 
Tabela 4 - Produtos que combinam dinamismo importador e exportador - "Dinâmicos"*

\begin{tabular}{|c|l|c|c|}
\hline $\begin{array}{c}\text { NCM-6 } \\
\text { dígitos }\end{array}$ & \multicolumn{1}{|c|}{ Descrição } & IVCR & $\begin{array}{c}\text { Taxa Crescimento } \\
\text { Importação- 2000-07 } \\
(\%)\end{array}$ \\
\hline 720293 & Ferroniobio & 63,3 & 1.822 \\
\hline 200911 & Sucos de laranjas,congelados,não fermentados & 55,2 & 1.388 \\
\hline 560721 & Cordéis de sisal/ outs.fibras "agave",p/atadeiras/enfard & 42,3 & 723 \\
\hline 90300 & Outros tipos de mate & 39,9 & 281.198 \\
\hline 320120 & Extrato tanante,de mimosa & 36,7 & 1.352 \\
\hline 20321 & Carcaças e meias-carcaças de suíno,congeladas & 35,6 & 17.532 \\
\hline 720110 & Ferro fundido bruto não ligado,c/peso<=0.5\% de fósforo & 32,6 & 12.818 \\
\hline 240130 & Desperdícios de fumo & 30,2 & 43.569 \\
\hline 330112 & Óleo essencial,de "petit grain" de laranja, outs.óleos & 30,2 & 404 \\
\hline 260112 & Minérios de ferro aglomerados e seus concentrados & 28,9 & 1.127 \\
\hline 90111 & Café não torrado,não descafeinado,em grão & 653 \\
\hline 260111 & Minérios de ferro não aglomerados e seus concentrados & 25,3 & 1.804 \\
\hline 120100 & Outros grãos de soja,mesmo triturados,soja p/semeadura & 23,5 & 405 \\
\hline 680300 & Ardósia natural trabalhada e obras de ardósia nat/aglom & 21,8 & 964 \\
\hline 930621 & Cartuchos p/espingardas/carabinas de cano liso & 21,3 & 99.403 \\
\hline 170199 & Outs. açucares de cana,beterraba,sacarose quedem.pura,sol. & 18,3 & 448 \\
\hline 80132 & Castanha de caju,fresca ou seca,sem casca & 18,0 & 5.945 \\
\hline 260600 & Bauxita não calcinada (minério de alumínio),outs & 17,0 & 9.057 \\
\hline 150710 & Óleo de soja,em bruto,mesmo degomado & 14,1 & 1.774 \\
\hline 722490 & Produtos semimanufaturados,de outras ligas de aços & 13,9 & 1.240 \\
\hline
\end{tabular}

Fonte: Aliceweb / Comtrade - Elaboração Própria.

* A lista completa encontra-se no Anexo.

Tabela 5 - Produtos mais exportados do Brasil para a China (em US\$)

\begin{tabular}{|c|c|c|c|c|c|c|c|}
\hline $\begin{array}{c}\text { NCM - } 6 \\
\text { dígitos }\end{array}$ & Descrição & 2000 & 2004 & 2006 & 2007 & $\begin{array}{l}\text { Variação } \\
\mathbf{2 0 0 0 - 0 7}\end{array}$ & $\begin{array}{l}\text { IVCR } \\
(2007) \\
\end{array}$ \\
\hline 260111 & Minérios de ferro não aglomerados e seus concentrados & 176,0 & 781,4 & $2.141,6$ & $3.118,9$ & $1672,4 \%$ & 25,3 \\
\hline 120100 & Outros grãos de soja,mesmo triturados,soja p/semeadura & 337,4 & $1.621,7$ & $2.431,6$ & $2.831,9$ & $739,4 \%$ & 23,5 \\
\hline 270900 & Óleos brutos de petróleo & 36,1 & 210,1 & 835,8 & 839,9 & $2225,0 \%$ & 1,4 \\
\hline 260112 & Minérios de ferro aglomerados e seus concentrados & 95,2 & 333,6 & 487,8 & 591,3 & $521,1 \%$ & 28,9 \\
\hline 470329 & Pasta quim.madeira de n/conif.a soda/sulfato,semi/branq & 53,7 & 252,2 & 347,8 & 385,6 & $618,3 \%$ & 34,6 \\
\hline 150710 & Óleo de soja,em bruto,mesmo degomado & 17,3 & 422,9 & 113,1 & 310,2 & $1689,8 \%$ & 14,1 \\
\hline 240120 & Fumo n/manuf.total/parc.destal.fls.secas, etc.virginia & 41,8 & 101,9 & 77,5 & 271,0 & $547,9 \%$ & 29,9 \\
\hline 720293 & Ferroniobio & 9,9 & 23,3 & 97,8 & 206,0 & $1985,3 \%$ & 63,3 \\
\hline 740311 & Catodos de cobre refinado/seus elementos, em forma bruta & 0,0 & 9,0 & 0,0 & 199,7 & 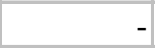 & 2,3 \\
\hline 720110 & Ferro fundido bruto não ligado,c/peso $<=0.5 \%$ de fós foro & 0,0 & 25,8 & 31,0 & 89,9 & & 32,6 \\
\hline 440799 & Madeira de amendoim,serrada/cortada em fls. outras & 15,4 & 82,0 & 105,8 & 66,8 & $334,5 \%$ & 8,6 \\
\hline 251612 & Granito cortado em blocos ou placas & 2,6 & 23,7 & 69,2 & 62,9 & $2309,1 \%$ & 39,8 \\
\hline 440729 & Madeira de cedro,serrada/cortada em folhas, outras madeiras & 5,8 & 39,1 & 48,4 & 46,8 & $703,4 \%$ & 17,4 \\
\hline 200911 & Sucos de laranjas,congelados,não fermentados & 2,2 & 31,0 & 43,4 & 45,3 & $1923,6 \%$ & $\mathbf{5 5 , 2}$ \\
\hline 390110 & Polietileno com carga, densidade $<0.94$,em forma primaria & 17,9 & 6,0 & 63,0 & 41,1 & $130,1 \%$ & 2,4 \\
\hline
\end{tabular}

Fonte: Aliceweb - Elaboração Própria. 
mais exportados, seis cresceram mais de mil por cento $(1.000 \%)$ após a abertura comercial ocorrida com a entrada da China na OMC, entre 2000 e 2007. Destaca-se, em primeiro lugar, "granito cortado em blocos ou placas", cujas exportações cresceram $2.309 \%$, passando de US $\$ 2,6$ milhões para US\$ 62,9 milhões, com um IVCR de 39,8 . O segundo produto com maior crescimento foi "óleos brutos de petróleo", que antes da entrada da China na OMC apresentava um volume de US\$ 36,1 milhões e, em 2007, atingiu a US\$ 839,9 milhões. Entre os principais produtos de exportação, "minérios de ferro" e "outros grãos de soja" o crescimento também foi significativo, de $1672 \%$ e $739 \%$, respectivamente. Cabe salientar dois produtos que antes da entrada da China na OMC sequer eram comercializados pelo Brasil para aquele país e que já estavam entre os vendidos em 2007, "catodos de cobre refinado" (US\$ 199 milhões) e "ferro fundido bruto" (US\$ 89,9 milhões). Portanto, é notório o crescimento das exportações brasileiras ocorridas com a abertura do mercado chinês, após sua entrada na OMC em 2001. Cabe ressaltar, o comprometimento da China em reduzir aproximadamente $96 \%$ nas tarifas sobre produtos primários como: arroz, trigo, grãos, óleos e açúcar, até 2011, o que deve contribuir para a manutenção do atual perfil da pauta brasileira de exportação para aquele país nos próximos anos.

Uma outra forma de examinar o perfil das exportações se baseia no seu conteúdo tecnológico. Atualmente, a classificação da OCDE, que divide os produtos desde commodities até de alta intensidade tecnológica, e se baseia nos gastos em P\&D em relação ao valor adicionado ou produção, tem sido bastante empregada para este fim. A partir dos 92 produtos com oferta exportável e dinamismo exportador brasileiro e dinamismo importador chinês, apenas 1 produto, "aviões a turboélice", ou $1,1 \%$ da amostra, apresentava alta intensidade tecnológica (tabela 6). Já os produtos de média-alta intensidade tecnológica chegavam a 32 , ou $34,8 \%$ dos 92 produtos selecionados. A maioria dos produtos, no entanto, se enquadra nas classificações de menor intensidade tecnológica (média-baixa e baixa tecnologia, além de commodities). Quando se examina os 20 produtos em que o Brasil apresenta a maior competitividade (maior IVCR), esta situação se torna ainda mais evidente, pois 17 são produtos de média-baixa intensidade tecnológica $(85 \%)$ e apenas três de média-alta tecnologia (tabela 7). Portanto, as exportações brasileiras para China devem se manter predominantemente em produtos de menor conteúdo tecnológico.
Tabela 6 - Produtos Dinâmicos segundo o Grau de Intensidade Tecnológica

\begin{tabular}{|l|c|c|}
\hline Classificação & Total & \% do Total \\
\hline Commodities & 11 & $12,0 \%$ \\
\hline Baixa & 22 & $23,9 \%$ \\
\hline Média-Baixa & 26 & $28,3 \%$ \\
\hline Média-Alta & 32 & $34,8 \%$ \\
\hline Alta & 1 & $1,1 \%$ \\
\hline Total & 92 & $100 \%$ \\
\hline
\end{tabular}
Própria.

Fonte: Comtrade / Aliceweb - Elaboração

Resultado semelhante foi obtido por Negri (2005), que concluiu que mais de $60 \%$ dos produtos da pauta exportadora brasileira para a China, em 2003, era constituída de commodities primárias, enquanto que na pauta exportadora para o mundo representavam apenas $40 \%$. Outra semelhança nos resultados é que mesmo após quatro anos da realização do estudo, os produtos de baixa e média intensidade tecnológica ainda predominam.

\section{CONCLUSÕES}

A China vem apresentando taxas de crescimento econômico extremamente elevadas há décadas e esta tendência se acentuou após sua entrada na OMC. No período de 1996 a 2001, houve uma média de crescimento de $8,6 \%$ ao ano. Após a adesão à $\mathrm{OMC}$, houve uma aceleração do crescimento econômico, com um crescimento médio de $10,5 \%$ entre 2001 e 2007 . As exportações chinesas também cresceram significativamente, passando de US\$ 295 bilhões, em 2002, para US\$ 1,2 trilhão, em 2007, registrando em um período de apenas cinco anos um crescimento de $306,7 \%$. $\mathrm{O}$ intercâmbio comercial obteve um aumento de 146,7\% (US\$ 851 bilhões em 2003 para US\$ 2,1 tri1hões em 2007). O comércio bilateral Brasil-China também cresceu de forma acelerada entre 2001 e 2007. As exportações brasileiras com destino a China passaram de US\$ 1,9 bilhão, em 2001, para US\$ 10,7 bilhões, em 2007, com sua participação no comércio total brasileiro crescendo de $2,8 \%$ para $8,3 \%$ ao longo do período.

Dado o grande crescimento do comércio bilateral e as perspectivas de ampliação futura, esse artigo procurou identificar aqueles produtos brasileiros com maiores oportunidades comerciais no mercado chinês, levando em consideração a 
Tabela 7 - Produtos Dinâmicos com vantagem comparativa revelada segundo o grau de intensidade tecnológica

\begin{tabular}{|c|l|r|c|}
\hline $\begin{array}{c}\text { NCM - 6 } \\
\text { dígitos }\end{array}$ & \multicolumn{1}{|c|}{ Descrição } & VCR & Tecnologia \\
\hline 720293 & Ferroniobio & 63,3 & Média - Baixa \\
\hline 200911 & Sucos de laranjas,congelados,não fermentados & 55,2 & Baixa \\
\hline 560721 & Cordéis de sisal/outs.fibras "agave",p/atadeiras/enfard & 42,3 & Baixa \\
\hline 90300 & Outros tipos de mate & 39,9 & Baixa \\
\hline 320120 & Extrato tanante,de mimosa & 36,7 & Média - Alta \\
\hline 20321 & Carcaças e meias-carcaças de suíno,congeladas & 35,6 & Baixa \\
\hline 720110 & Ferro fundido bruto não ligado, c/peso<=0.5\% de fósforo & 32,6 & Média - Baixa \\
\hline 240130 & Desperdícios de fumo & 30,2 & Commodities \\
\hline 330112 & Óleo essencial,de "petit grain" de laranja, outs.óleos & 30,2 & Média - Alta \\
\hline 260112 & Minérios de ferro aglomerados e seus concentrados & 28,9 & Commodities \\
\hline 90111 & Café não torrado,não descafeinado,em grão & 28,4 & Commodities \\
\hline 260111 & Minérios de ferro não aglomerados e seus concentrados & 25,3 & Commodities \\
\hline 120100 & Outros grãos soja, mesmo triturados,soja p/semeadura & 23,5 & Commodities \\
\hline 680300 & Ardósia natural trabalhada e obras de ardósia nat/aglom & 21,8 & Média - Baixa \\
\hline 930621 & Cartuchos p/espingardas/carabinas de cano liso & 21,3 & Média - Alta \\
\hline 170199 & Outs. açucares de cana, beterraba, sacarose pura,sol. & 18,3 & Baixa \\
\hline 80132 & Castanha de caju,fresca ou seca,sem casca & 18,0 & Baixa \\
\hline 260600 & Bauxita não calcinada (minério de alumínio),outs & 17,0 & Commodities \\
\hline 150710 & Óleo de soja,em bruto,mesmo degomado & 14,1 & Baixa \\
\hline 722490 & Produtos semimanufaturados,de outras ligas de aços & 13,9 & Média - Baixa \\
\hline & & & \\
\hline
\end{tabular}

Fonte: Aliceweb - Elaboração Própria.

* A lista completa encontra-se no Anexo.

existência e a competitividade da oferta exportável brasileira e o crescimento das importações chinesas. Os resultados obtidos a partir da competitividade exportadora do Brasil, medida através do IVCR, e do dinamismo importador chinês, mostram que apenas 92 produtos de um universo de 5302 a seis dígitos da NCM se encaixam nesse perfil. $\mathrm{O}$ foco das exportações brasileiras para o mercado chinês deve se concentrar nestes produtos, pois além de o Brasil ser competitivo, a China apresenta uma demanda de importações crescendo acima da média. A análise qualitativa desses produtos mostrou que eles são, em sua maioria, de menor intensidade tecnológica (média-baixa e baixa tecnologia, além de commodities). Quando se examina os 20 produtos em que o Brasil apresenta a maior competitividade (maior IVCR), esta situação se torna ainda mais evidente, pois 17 são produtos de média-baixa intensidade tecnológica (85\%) e apenas três de média-alta tecnologia.

Outro aspecto importante desse estudo é a constatação que a maior parte das exportações efetivas do Brasil para a China já se concentra nesses 92 produtos identificados pela metodologia utilizada, embora os mais exportados não apresentarem necessariamente a maior vantagem comparativa revelada. "Ferroniobio" (com IVCR de
63,32), e "sucos de laranja" (com IVCR 55,20), por exemplo, apresentaram os maiores IVCR, porém, ocupam respectivamente apenas a $8^{\mathrm{a}} \mathrm{e} 18^{\mathrm{a}}$ posição no ranking dos produtos mais exportados para China. No entanto, especialmente os mais exportados, "minérios de ferro" e "outros grãos de soja", também são bastante competitivos, com IVCR superior a 20. Por sinal, em 2007, aproximadamente $62 \%$ do total das vendas brasileiras para a China concentraram-se basicamente nesses dois grupos de produtos, "Minérios escorias e cinzas" $(35,4 \%)$ e "Sementes e frutos oleaginosos, grãos" (26,3\%). Portanto, a partir dos resultados encontrados e da pauta efetiva de exportações brasileiras para a China, pode-se inferir que as exportações brasileiras para aquele país devem se manter predominantemente em produtos de menor conteúdo tecnológico.

\section{REFERÊNCIAS BIBLIOGRÁFICAS}

ALICEWEB. Indicadores Econômicos de Importação e Exportação. Disponível em: <http://aliceweb. desenvolvimento.gov.br>. Último acesso em: 1 de 
março de 2009.

BALASSA, Bela. Trade liberalization and revealed comparative advantage. The Manchester School of Economic and Social Studies, v.23, p.99-124, 1965.

BARBOSA, Alexandre E.; WAQUIL, Paulo D. O Rumo das Exportações Agrícolas Brasileiras frente às Negociações para a Formação da Área de Livre Comércio das Américas (ALCA). Indicadores Econômicos FEE, v.29, p. 71-85, 2001.

BARBOSA, Alexandre F.; MENDES, Ricardo C. As Relações Econômicas entre Brasil e China: Uma Parceria Difícil - Dialogue on Globalization - Briefing Papers Fes. Brasil, 2006.

BENDER, S. Conflitos e convergências na ALCA numa perspectiva de vantagens comparativas reveladas de países das Américas. Revista de Economia Aplicada, São Paulo, Brasil, v.10, p.111-135, 2006.

BERNARDES, Roberto. Produção de estatísticas e inovação tecnológica. Paep 1996-2001. São Paulo: Perspec. Vol.17 n 3-4. São Paulo, 2003.

CASTILHOS, Marta R. Impactos distributivos do comércio Brasil-China: Efeitos da Intensificação do comércio bilateral sobre o mercado de trabalho brasileiro. Revista Brasileira de Comércio Exterior, Rio de Janeiro, nº 91, 2007.

CELESTINI, Juliana. O Final do Acordo sobre Têxteis e Vestuário e a Competitividade na Indústria Têxtil Brasileira. Dissertação de Mestrado, Universidade do Vale do Rio dos Sinos. São Leopoldo, 2006.

COMTRADE. United Nations Commodity Trade Statistics Database. Disponível em: <http:// comtrade.un.org/db>. Último Acesso em: 20 de fevereiro de 2009.

CORONEL, Daniel A.; MACHADO, João A.; PEDROZO, Eugenio Á.; SILVA, Mariângela A. Vantagens Comparativas Reveladas e Orientação Regional da Soja Brasileira em Relação à China. XLV Congresso da Sociedade Brasileira de Economia, Administração e Sociologia Rural. Londrina: SOBER, julho, 2007.

DICK, Patrícia P. A parceria estratégica entre Brasil-China: A contribuição da política externa brasileira (1995-2005). Porto Alegre: UFRGS, 2006.
FERRAZ, João C. Made in Brazil: Desafios Competitivos para a indústria. Rio de Janeiro: Campus, 1995.

FERRAZ, Galeno; RIBEIRO, Fernando. Brasil-China: Desempenho exportador global e competição nos mercados da União Européia e dos Estados Unidos. Revista Brasileira de Comércio Exterior, $\mathrm{n}^{\circ}$ 80, 2004.

FURTADO, André T.; CARVALHO, Ruy Q. Padrões de intensidade tecnológica da indústria brasileira: um estudo comparativo com os países centrais. São Paulo: Perspec. Vol.19, 2005.

HAGUENAUER, Lia. Competitividade: Conceitos e Medidas. Uma Resenha da Bibliografia Recente com Ênfase no Caso Brasileiro. Rio de Janeiro: UFRJ/IEI, 1989.

HOLANDA, Marcos C. Dinâmica e Determinantes da Vantagem Comparativa: O exemplo Asiático. Ceará: Universidade Federal do Ceará. Texto para Discussão n²30, 2002.

KATZ, J.; STUMPO, G. Regimes sectoriales, productividad y competitividad internacional. Revista de la Cepal, n. 75, p. 137-159, 2001.

KUME, H.; PIANI, Guida. ALCA: uma estimativa do impacto no comércio bilateral Brasil-Estados Unidos. Economia e Sociedade, Campinas, v. 17, p. 215-233, 2005.

MACHADO, João B.; SERAPIÃO, Carlos Jr. Brasil-Rússia: Relações Econômicas Bilaterais: Perspectivas de Ampliação. Revista Brasileira de Comércio Exterior, $\mathrm{n}^{\circ}$ 76, 2003.

MAIA, Sinézio F. Impactos da abertura econômica sobre as exportações agrícolas brasileiras: analise comparativa. In: XL Congresso Brasileiro da Sociedade Brasileiro de Economia e Sociologia Rural. Passo Fundo: SOBER, Anais, 2002.

MARKWALD, Ricardo. Intensidade Tecnológica e Dinamismo das Exportações Brasileiras. Revista Brasileira de Comércio Exterior, Rio de Janeiro, $\mathrm{n}^{\circ}$ 79, 2004.

MATTOS, Michelle. Padrões de Especialização no Comércio Brasil-China. Universidade Federal de Santa Catarina. Florianópolis: UFSC, 2008.

MDIC - Ministério do Desenvolvimento Indústria e 
Comercio Exterior. China: Intercâmbio Comercial, tarifas aduaneiras, barreiras em bens e serviços e compromissos na acessão à OMC. Disponível em: $<$ http://www.mdic.gov.br/sitio>. Último acesso em: 20 de janeiro de 2009.

MRE - Ministério das Relações Exteriores. Departamento de Promoção Comercial. Divisão de Informação Comercial. Como Exportar - República Popular da China. Estudos e Documentos de Comércio Exterior. Brasília, 2008.

NEGRI, Fernanda. O Perfil dos exportadores industriais brasileiros para a China. Revista Brasileira de Comércio Exterior. Rio de Janeiro, n. 84, p. 22-35, 2005.

NETO, Luiz G. Criação e desvio de comércio o Mercosul: Uma aplicação do índice de vantagem comparativa revelada modificado (no período de 1986 a 1996), Porto Alegre: UFRGS, 1999.

OMC. ORGANIZAÇÃO MUNDIAL DO COMÉRCIO. Disponível em: <http:\\www.wto.org>. Último Acesso em: 17 de outubro de 2008.

RIBEIRO, Fernando; POURCHET, Henry. O perfil do comércio Brasil-China. Revista Brasileira de Comércio Exterior. Rio de Janeiro, no 79, p.13- 33, abr. 2004.

SECEX - SECRETARIA DE COMÉRCIO EXTERIOR. Disponível em: <http://www2.desenvolvimento.gov.br/sitio/secex/secex/competencia.php>. Último acesso em: 20 de janeiro de 2009.

SIRILLI, G. Old and new paradigms in the measurement of R\&D. Science and Public Policy, v. 25. 1998.

WAQUIL, P. D.; ALVIM, A. M.; SILVA, L. X. e TRAPP, G. P. Vantagens comparativas reveladas e orientação regional das exportações agrícolas brasileiras para a União Européia. In: XLII Congresso Brasileiro de Economia e Sociologia Rural. Cuiabá, MT: SOBER, 2004. 


\section{Anexo}

92 Produtos "Dinâmicos"

Combinam Dinamismo Exportador Brasileiro Importador Chinês

\begin{tabular}{|c|c|c|c|c|}
\hline $\begin{array}{l}\text { NCM-6 } \\
\text { dígitos }\end{array}$ & Descrição & & $\begin{array}{l}\text { Taxa Crescimento } \\
\text { Importação 2000-07 } \\
(\%)\end{array}$ & $\begin{array}{l}\text { Intensidade } \\
\text { Tecnológica }\end{array}$ \\
\hline 720293 & Ferroniobio & 63,3 & 1.822 & Média - Baixa \\
\hline 200911 & Sucos de laranjas,congelados,não fermentados & 55,2 & 1.388 & Baixa \\
\hline 560721 & Cordéis de sisal/outs.fibras "agave",p/atadeiras/enfard & 42,3 & 723 & Baixa \\
\hline 90300 & Outros tipos de mate & 39,9 & 281.198 & Baixa \\
\hline 320120 & Extrato tanante,de mimosa & 36,7 & 1.352 & Média - Alta \\
\hline 20321 & Carcaças e meias-carcaças de suíno,congeladas & 35,6 & 17.532 & Baixa \\
\hline 720110 & Ferro fundido bruto não ligado,c/peso $<=0.5 \%$ de fósforo & 32,6 & 12.818 & Média - Baixa \\
\hline 240130 & Desperdícios de fumo & 30,2 & 43.569 & Commodities \\
\hline 330112 & Óleo essencial,de "petit grain" de laranja, outs.óleos & 30,2 & 404 & Média - Alta \\
\hline 260112 & Minérios de ferro aglomerados e seus concentrados & 28,9 & 1.127 & Commodities \\
\hline 90111 & Café não torrado,não descafeinado,em grão & 28,4 & 653 & Commodities \\
\hline 260111 & Minérios de ferro não aglomerados e seus concentrados & 25,3 & 1.804 & Commodities \\
\hline 120100 & Outros grãos de soja,mesmo triturados,soja p/semeadura & 23,5 & 405 & Commodities \\
\hline 680300 & Ardósia natural trabalhada e obras de ardósia nat/aglom & 21,8 & 964 & Média - Baixa \\
\hline 930621 & Cartuchos p/espingardas/carabinas de cano liso & 21,3 & 99.403 & Média - Alta \\
\hline 170199 & Outs. açucares de cana,beterraba,sacarose quedem.pura,sol. & 18,3 & 448 & Baixa \\
\hline 80132 & Castanha de caju,fresca ou seca,sem casca & 18,0 & 5.945 & Baixa \\
\hline 260600 & Bauxita não calcinada (minério de alumínio),outs & 17,0 & 9.057 & Commodities \\
\hline 150710 & Óleo de soja,em bruto,mesmo degomado & 14,1 & 1.774 & Baixa \\
\hline 722490 & Produtos semimanufaturados, de outras ligas de aços & 13,9 & 1.240 & Média - Baixa \\
\hline 280469 & Outros silícios & 13,6 & 3.269 & Média - Alta \\
\hline 30611 & Outras lagostas,congeladas, exceto as inteiras,outs & 12,9 & 1.720 & Baixa \\
\hline 210111 & Café solúvel,mesmo descafeinado,outs. Extratos, essências & 12,5 & 894 & Baixa \\
\hline 846781 & Serras de corrente, de uso manual & 8,6 & 462 & Média - Alta \\
\hline 400259 & Borracha de acrilonitrila-butadieno em chapas, fls.etc. & 8,5 & 429 & Média - Alta \\
\hline 160232 & Preparações alimentícias e conservas, de galos,galinhas & 8,1 & 2.486 & Baixa \\
\hline 80450 & Mangostoes frescos ou secos, goiabas frescas ou secas & 7,7 & 580 & Baixa \\
\hline 760511 & Fios de alumínio n/lig.sec.transv $>7 \mathrm{~mm}, \mathrm{re}<=0.0283 \mathrm{ohm} . \mathrm{mm} 2$, outs. Fios & 7,2 & 478 & Média - Baixa \\
\hline 260200 & Minérios de manganês aglomerados e seus concentrados, outs. Minérios & 7,1 & 1.263 & Commodities \\
\hline 720299 & Ferrofosforos, outs. Ferroligas & 6,5 & 780 & Média - Baixa \\
\hline 850153 & Motor eletr.corr.altern.trif. $75 \mathrm{kw}<$ pot $<=7500 \mathrm{kw}$, outs.motores & 6,1 & 954 & Média - Alta \\
\hline 520100 & Algodão não debulhado,não cardado nem penteado,outs.tipos & 6,0 & 4.592 & Commodities \\
\hline 20130 & Carnes desossadas de bovino, frescas ou refrigeradas & 5,9 & 1.052 & Baixa \\
\hline 841090 & Partes de turbinas e rodas hidráulicas,incl.reguladores & 5,8 & 680 & Média - Alta \\
\hline 845530 & Cilindros de laminadores,fundidos, de aço/ferro nodular, outs. Cilindros & 5,4 & 904 & Média - Alta \\
\hline 440122 & Madeira de não coníferas,em estilhas ou em partículas & 4,7 & 11.783 & Commodities \\
\hline 290220 & Benzeno & 4,6 & 780 & Média - Alta \\
\hline 180400 & Manteiga,gordura e óleo,de cacau & 4,1 & 495 & Baixa \\
\hline 750110 & Mates de níquel & 3,9 & 1.516 .180 & Média - Baixa \\
\hline 291712 & Acido adipico, sais do acido salicílico & 3,8 & 941 & Média - Alta \\
\hline 640399 & Outros calcados de couro natural sol.ext.borr/plást. & 3,7 & 1.883 & Baixa \\
\hline 720221 & Ferrossilicio contendo peso $>55 \%$ de silício & 3,5 & 859 & Média - Baixa \\
\hline 940350 & Moveis de madeira p/quartos de dormir & 3,3 & 476 & Baixa \\
\hline 850152 & Motor eletr.corr.altern.trif. $750 \mathrm{w}<\mathrm{p}<=75 \mathrm{kw}$,rotor anéis, outs motores & 3,3 & 799 & Média - Alta \\
\hline 640391 & Outros calcados de couro natural,cobrindo o tornozelo & 3,1 & 56.513 & Baixa \\
\hline
\end{tabular}


Tabela 1 Continuação

92 Produtos "Dinâmicos"

Combinam Dinamismo Exportador Brasileiro Importador Chinês

\begin{tabular}{|c|c|c|c|c|}
\hline 880240 & Aviões a turboelice,etc.peso>15000kg,vazios,outros aviões & 3,1 & 494 & Alta \\
\hline 401120 & Pneus novos para ônibus ou caminhões, medida $=11,00-24$, outs. pneus & 2,9 & 1.295 & Média - Baixa \\
\hline 870423 & Chassis c/motor diesel e cabina,carga >20t, out.veículos & 2,8 & 466 & Média - Alta \\
\hline 420500 & Outras obras de couro natural ou reconstituído & 2,7 & 818 & Baixa \\
\hline 640359 & Calç. C/sola mad.s/palm., e biq.prot.d/metal,outs calçados & 2,7 & 1.249 & Baixa \\
\hline 848310 & Arvores de "cames" para comando de válvulas, manivelas & 2,6 & 919 & Média - Alta \\
\hline 800110 & Estanho não ligado,em forma bruta & 2,5 & 2.374 & Média - Baixa \\
\hline 722850 & Barras de outras ligas de aços, obtidas/acabadas a frio & 2,5 & 418 & Média - Baixa \\
\hline 180310 & Pasta de cacau,não desengordurada & 2,4 & 552 & Baixa \\
\hline 860799 & Outras partes de veículos $p / v i a s$ férreas & 2,4 & 975 & Média - Alta \\
\hline 740311 & Catodos de cobre refinado/seus elementos, em forma bruta & 2,3 & 751 & Média - Baixa \\
\hline 720230 & Ferrossilicio-manganes & 2,2 & 142.309 & Média - Baixa \\
\hline 440121 & Madeira de coníferas,em estilhas ou em partículas & 2,1 & 2.266 & Commodities \\
\hline 291020 & Metiloxirano (oxido de propileno) & 2,0 & 1.313 & Média - Alta \\
\hline 400270 & Borracha de etileno-propileno-dieno n/conjug.em chapas, & 2,0 & 563 & Média - Alta \\
\hline 400220 & Borracha de butadieno (br),em chapas,folhas, tiras, etc. Óleo de borracha & 2,0 & 714 & Média - Alta \\
\hline 400219 & Borracha de estireno-butadieno,em chapas,folhas,tiras & 2,0 & 442 & Média - Baixa \\
\hline 854620 & Isoladores de cerâmica p/uso elétrico & 2,0 & 430 & Média - Baixa \\
\hline 841810 & Refrigeradores combin.c/congeladores, porta ext.separada & 1,8 & 1.896 & Média - Alta \\
\hline 720852 & Lamin.ferro/aço, quente, $1>=60 \mathrm{~cm}, \mathrm{n} /$ enrolado, $4.75<=e<=10 \mathrm{~mm}$ & 1,8 & 601 & Média - Baixa \\
\hline 850710 & Acumuladores eletr.de chumbo,p/arranque de motor pistão & 1,8 & 523 & Média - Alta \\
\hline 851110 & Velas de ignição p/motor explosão/diesel & 1,8 & 645 & Média - Alta \\
\hline 722530 & Lamin.de outras ligas aços, quente, $\mid>=600 \mathrm{~mm}$, rolos & 1,8 & 4.497 & Média - Baixa \\
\hline 401110 & Pneus novos para automóveis de passageiros & 1,7 & 1.406 & Média - Baixa \\
\hline 848220 & Outros rolamentos de roletes cônicos, de carga radial & 1,7 & 1.367 & Média - Alta \\
\hline 391710 & Tripas artificiais de outros plásticos celulósicos, outs & 1,6 & 565 & Média - Baixa \\
\hline 640419 & Outs.calcados de matéria textil,sola de borracha/plast. & 1,5 & 1.719 & Baixa \\
\hline 870850 & Eixos d/transm.c/diferencial p/veícs.automs. & 1,4 & 911 & Média - Alta \\
\hline 870893 & Embreagens e suas partes p/tratores/veículos automóveis & 1,4 & 1.389 & Média - Alta \\
\hline 750210 & Catodos de níquel não ligado,em forma bruta, outs. Formas brutas & 1,4 & 5.255 & Média - Baixa \\
\hline 847420 & Maqs.e apars.p/esmagar,etc.subst.miner.sólida,de bolas, outs.maqs. & 1,4 & 463 & Média - Alta \\
\hline 270900 & Óleos brutos de petróleo & 1,4 & 437 & Commodities \\
\hline 292610 & Acrilonitrila & 1,3 & 424 & Média - Alta \\
\hline 640299 & Outros calçados de borracha ou plástico & 1,3 & 5.789 & Baixa \\
\hline 820750 & Brocas helicoidais, $\mathrm{d}<=52 \mathrm{~mm}$, de met.comuns, incl. diamantad, outras & 1,3 & 536 & Média - Baixa \\
\hline 290122 & Propeno (propileno) não saturado & 1,3 & 953 & Média - Alta \\
\hline 790111 & Zinco $n /$ lig.cont.zinco >=99.99\%, eletrolítico,em lingotes & 1,2 & 1.958 & Média - Baixa \\
\hline 720260 & Ferroniquel & 1,2 & 32.260 & Média - Baixa \\
\hline 681310 & Outras guarnições não montadas,p/freios, de amianto,pastilhas etc. & 1,2 & 1.050 & Média - Baixa \\
\hline 940360 & Outros moveis de madeira & 1,2 & 1.605 & Baixa \\
\hline 840734 & Outros motores de explosão,p/veic.cap.87,sup.1000cm3 & 1,2 & 780 & Média - Alta \\
\hline 870323 & Automóveis c/motor explosão, $1500<\mathrm{cm} 3<=3000$, ate e sup 6 passag & 1,2 & 611 & Média - Alta \\
\hline 700910 & Espelhos retrovisores para veículos & 1,2 & 451 & Média - Baixa \\
\hline 870880 & Amortecedores de suspensão p/tratores e veic.automóveis & 1,1 & 546 & Média - Alta \\
\hline 851150 & Dínamos e alternadores p/motor explosão/diesel,outs.geradores & 1,1 & 550 & Média - Alta \\
\hline 870421 & Chassis c/motor diesel e cabina,p/carga<=5t, outros veículos & 1,1 & 608 & Média - Alta \\
\hline 401693 & Juntas, gaxetas, semelhs. de borracha vulcan.n/endurecida & 1,0 & 533 & Média - Baixa \\
\hline
\end{tabular}

Fonte: Aliceweb - Elaboração Própria. 